\title{
INCORPORAÇÃO DE ESCÓRIA DE ALTO FORNO A CARVÃO VEGETAL EM MASSA DE CERÂMICA VERMELHA
}

\author{
Alexandre Zaccaron ${ }^{1 *}$, Paulo Fernandes ${ }^{2}$, Vitor de Souza Nandi ${ }^{2}$, Fábio Rosso ${ }^{2}$ \\ ${ }^{1}$ Programa de Pós-Graduação em Ciência e Engenharia de Materiais - Universidade do Extremo Sul \\ Catarinense - UNESC \\ 2 Departamento de Engenharia Cerâmica - Centro Universitário Barriga Verde - UNIBAVE \\ *alexandrezaccaron@hotmail.com
}

\section{Resumo:}

O presente estudo propõe a adição do resíduo gerado no processo metalúrgico, mais precisamente a escória de alto forno a carvão vegetal usado como agente redutor na cadeia produtiva. Além da massa padrão, foram feitas 3 formulações com a incorporação desse resíduo, em 5, 10 e 20\%. As peças foram queimadas em três temperaturas, 850,900 e $950{ }^{\circ} \mathrm{C}$ e as propriedades tecnológicas estudadas foram: retração térmica linear de secagem e queima, absorção de água, perda ao fogo e resistência mecânica à compressão na peça seca e na peça queimada. Os resultados obtidos, mostram que até $20 \%$ de adição do resíduo na massa padrão, consegue-se atingir os limites estabelecidos por norma na fabricação de blocos de vedação, em escala laboratorial, dentro das três temperaturas estudadas.

Palavas-chave: Valorização de resíduos, cerâmica vermelha, escória de carvão.

\section{INTRODUÇÃO}

A atividade de recuperação de subprodutos é indispensável em face da necessidade de proteção ambiental. As indústrias siderúrgicas, em especial, produzem grande quantidade de resíduos, em função do processo de produção do aço. Estabelecer formas para o aproveitamento destes resíduos é um dos grandes desafios da sociedade moderna ${ }^{1}$.

Na produção do aço, o carvão (vegetal ou mineral) exerce dupla função: Como combustível, permite alcançar altas temperaturas necessárias à fusão do minério. Como redutor, associa-se ao oxigênio que se desprende do minério com a alta temperatura, deixando livre o ferro. A remoção do oxigênio do ferro para ligar-se ao carbono ocorre no interior do alto-forno, e é conhecido como processo de redução. Neste processo, o ferro se liquefaz e é chamado de ferro gusa. Impurezas como o calcário, sílica, etc., formam a escória, que é o principal resíduo do alto forno ${ }^{2}$.

As principais matérias-primas para a produção do ferro-gusa são o minério de ferro e os fundentes, principalmente o calcário e a sílica. O carvão vegetal é utilizado como agente redutor do processo. O carvão metalúrgico, transformado em coque, é o principal redutor em uso no mundo, mas o Brasil não dispõe de reservas por isso utilizam o carvão vegetal como combustível, pois no Brasil, além do clima ser favorável ao plantio de florestas de eucalipto para a produção de carvão vegetal, existem áreas disponíveis para a plantação ${ }^{3}$. A fim de se diminuir os impactos ambientais associados às emissões atmoféricas, pesquisas ao redor do mundo estão investindo fortemente na incerção de biomassa como fonte energética ${ }^{4-6}$. 
Para o Ministério Brasileiro do Meio Ambiente (MMA) ${ }^{7}$, uma das principais vantagens da biomassa é que seu aproveitamento pode ser feito diretamente, por meio da combustão em fornos, caldeiras, etc. Para que seja aumentada a eficiência e sejam reduzidos os impactos socioambientais no processo de sua produção, porém, estão sendo desenvolvidas e aperfeiçoadas tecnologias de conversão mais eficientes como a gaseificação e a pirólise, também sendo comum a co-geração em sistemas que utilizam a biomassa como fonte energética. Outra importante vantagem é que o aumento na sua utilização pode estar associado à redução no consumo de combustíveis fósseis, como o petróleo e seus derivados, que não são matérias-primas renováveis.

A biomassa é uma das fontes para produção de energia com maior potencial de crescimento nos próximos anos. Tanto no Brasil quanto no restante do mundo, ela é considerada uma das proncipais alternativas para diversificação da matriz energética e a consequente redução da dependência dos combustiveis fósseis ${ }^{8,9}$. Diante desse cenário, deve-se discutir a cerca de outro problema recorrente, a geração dos resíduos provenientes do processo de combustão dos insumos energéticos, pois com o crescimento do uso de biomassa como fonte de energia, haverá um aumento da demanda de insumos (bagaço de cana, palha, casca de arroz, vinhoto, lenha...) e consequentemente uma geração maior de resíduos proveniente da queima desses materiais e de outras diferentes etapas do processo produtivo.

De acordo com Almeida e Melo (2001) $)^{3}$, a produção de escória de alto forno é de aproximadamente 836 mil toneladas por ano, e segundo análises realizadas por algumas empresas do setor, de acordo com a ABNT NBR 10004/2004 ${ }^{10}$, a escória é um resíduo classe II-A (não inerte). Diante desta considerável geração de resíduos é de suma importância a implantação de um sistema de gestão dos resíduos sólidos siderúrgicos.

Uma das propostas atuais está na reutilização de resíduos a fim de minimizar os impactos ambientais recorrentes da má deposição de rejeitos, tornando-os assim, uma matéria prima em outros processos produtivos. A reciclagem de resíduos, independentemente do seu tipo, apresenta várias vantagens em relação à utilização de recursos naturais "virgens", dentre as quais se tem: redução do volume de extração de matérias-primas, redução do consumo de energia, menores emissões de poluentes e melhoria da saúde e segurança da população. Nos últimos anos, a pesquisa sobre a reciclagem de resíduos industriais vem sendo intensificada em todo o mundo ${ }^{11}$.

A cerâmica vermelha ou tradicional é atualmente um dos setores da indústria cerâmica que vem utilizando como uma alternativa viável a incorporação de diversos resíduos como forma de minimizar os impactos ao meio ambiente, além do reaproveitamento como matéria-prima em substituição de outros materiais ${ }^{12}$. Estudos recentes mostram que o uso de cerâmica vermelha como fonte de valorização de resíduos é uma opção bastante viável, a bibliografia traz o aproveitamento de resíduos da mineração de carvão ${ }^{13}$, pó de mármore ${ }^{14}$, e alguns com relevância ao estudo, como: cinzas de casca de arroz, bagaço de cana-de-açucar, lenha, entre outros $^{15-20}$

Diante disso, o presente estudo tem como objetivo adicionar o resíduo proveniente do resfriamento das caldeiras das Usinas de biomassa, empregando essa escória in natura em massa de cerâmica vermelha, avaliando as propriedades técnicas do material e comparando a uma massa padrão industrial e também a literatura e normas técnicas, principalmente em relação às seguintes propriedades tecnológicas: retração linear de secagem e queima, perda ao fogo, absorção de água e resistência mecânica do produto final, propriedades estas fundamentais para a produção de cerâmica vermelha.

Portanto, verificar a viabilidade de emprego da escória de biomassa em cerâmica vermelha fomenta diretamente a minimização de matérias-primas a serem utilizadas no processo produtivo, o que reflete diretamente na conservação de fontes não renováveis bem como na reciclagem de resíduos. 


\section{MATERIAIS E MÉTODOS}

Foi utilizada no estudo a massa padrão de uma empresa de cerâmica vermelha da mesoregião central do estado do Maranhão, que coletou o material de seu processo e enviou ao laboratório. A escória de biomassa, proveniente do resfriamento das caldeiras, também foi enviada pela cerâmica, que coletou o material em uma usina da mesma região, e assim como a massa padrão, encaminhou ao laboratório, onde passou pelo processo de moagem em moínho de martelos (Modelo CT-058, Marca Servitech) para desagregamento dos blocos maiores.

O ensaio de resíduo bruto, mostra a quantia de material não-argiloso é encontrado na massa padrão, e a porção de material que não pode ser desagregado sem o auxílio de alguma ferramenta ou método de cominuição. Esse teste foi realizado em peneira de malha \#325 MESH $(44 \mu \mathrm{m})$ na massa cerâmica padrão estudada.

Foram desenvolvidas três formulações além da massa padrão (STD), utilizando diferentes percentuais (5, 10 e 20\%). As amostras foram caracterizadas dentro das seguintes propriedades: retração de secagem, retração de queima, perda ao fogo, absorção de água e resistência mecânica a seco e resistência mecânica pós queima.

O método escolhido para avaliar o teor de plasticidade da massa foi o de Pfefferkorn, que consiste em obter uma deformação de $30 \%$ dos corpos-de-prova com auxílio de um plasticímetro, que define o percentual de água ideal da matéria-prima ${ }^{21-22}$.

Após a homogeneização das formulações, iniciou-se o processo de confecção das amostras. As mesmas foram preparadas manualmente, em um molde de PVC com diâmetro e altura aproximadas de $27 \mathrm{~mm}$ e $50 \mathrm{~mm}$.

Após a conformação, as amostras passaram por secagem natural durante 24 horas, na sequencia, passou por secagem forçada em estufa (elétrica, marca DeLeo $n^{\circ} 2211$, tipo: 8) a uma temperatura de $50 \pm 10^{\circ} \mathrm{C}$ por mais 24 horas. Após a etapa de secagem, os corpos-de-prova foram queimadas em forno laboratorial tipo mufla (Jung, Modelo J200), com taxa de aquecimento de $2{ }^{\circ} \mathrm{C} / \mathrm{min}, 3$ temperaturas de queima: 850, $900 \mathrm{e}$ $950{ }^{\circ} \mathrm{C}$ e tempo de patamar de 2 horas.

Após o tratamento térmico, as amostras passaram pela caracterização, para obtenção dos resultados a serem avaliados.

O ensaio de resistência mecânica foi realizado em uma máquina universal de ensaios (modelo DL-20000, marca EMIC), onde, para avaliar sua carga de ruptura o equipamento opera com velocidade constante de $30 \mathrm{~mm} / \mathrm{min}$ e limite de força de $9000 \mathrm{~N}$. Esse ensaio foi realizado com os corpos-de-prova crus e secos, para analisar qual o comportamento das peças para manuseio antes da queima; e também foi realizado com os corpos-de-prova pós-queima, conforme NBR 15270-01/200523,24.

\section{APRESENTAÇÃO E ANÁLISE DOS DADOS}

O teor de plasticidade das amostras foi realizado pelo método de Pfefferkor, que consiste em buscar o melhor teor de umidade no plasticímetro. A Tabela 01 apresenta os teores de umidade ideal para que as amostragem tenham seu melhor desempenho de trabalho.

Tabela 01: Percentual de umidade ideal por método de Pfefferkorn das amostras estudadas.

\begin{tabular}{ccccc}
\hline Amostras & STD & $\mathbf{5 \%}$ & $\mathbf{1 0 \%}$ & $\mathbf{2 0 \%}$ \\
\hline Umidade ideal (\%) & 22,99 & 22,49 & 21,19 & 20,44 \\
\hline
\end{tabular}

Pode-se observar que com o aumento da incorporação do resíduo, diminui-se o uso de água para obtenção da umidade ideal para trabalho das amostras. Esse fato se dá, pois quanto maior a quantia de material argiloso mais a necessidade de água para que ele atinja o índice de plasticidade ideal, ou seja, com a adição de um 
material não-argiloso na composição tera-se-á uma diminução gradativa da necessidade de água para que esse índice seja atingido.

Na Tabela 02, é apresentado o percentual de resíduo retido em peneira \#325 MESH (44 $\mu \mathrm{m})$, sendo o material não-argiloso encontrado na massa padrão.

Tabela 02: Percentual de resíduo bruto retido em peneira com malha $325 \mathrm{MESH}$.

\begin{tabular}{cc}
\hline Amostragem & Resíduo Bruto (\%) \\
\hline STD & 16,0 \\
\hline
\end{tabular}

O ensaio de resíduo bruto determina a qualidade do produto, dimensões, resistência mecânica, absorção de água, velocidade de extrusão, secagem e queima. Para obterem-se melhores resultados fabris, o resíduo bruto da massa cerâmica deve estar aproximadamente em $15 \%{ }^{25}$.

A Figura 01 ilustra o gráfico com os resultados de retração térmica linear de secagem, onde é possível observar que a retração linear de secagem diminui conforme há um aumento no percentual do resíduo nas formulações. A retração de secagem é importante para controlar a dimensão final da peça cerâmica. Esse fenômeno ocorre pelo fato do resíduo reagir como material inerte, minimizando a redução do tamanho inicial de conformação da peça. A minimização da retração influenciada pelo resíduo incorporado ocorre devido à mínima reação de água entre estes materiais e as partículas de argilominerais. À medida que a água é retirada pela secagem, os percentuais de resíduo praticamente se mantêm em seu tamanho original, mantendo consigo a estrutura da peça, e diminuindo assim, a deformação com a retirada da água ${ }^{22}$. Em um estudo recente, Crozetta et al. $(2016)^{26}$, comprovaram a importancia do resíduo para secagem e diminuição da variação dimencional ocasionada durante a perda de umidade do corpo cerâmico.

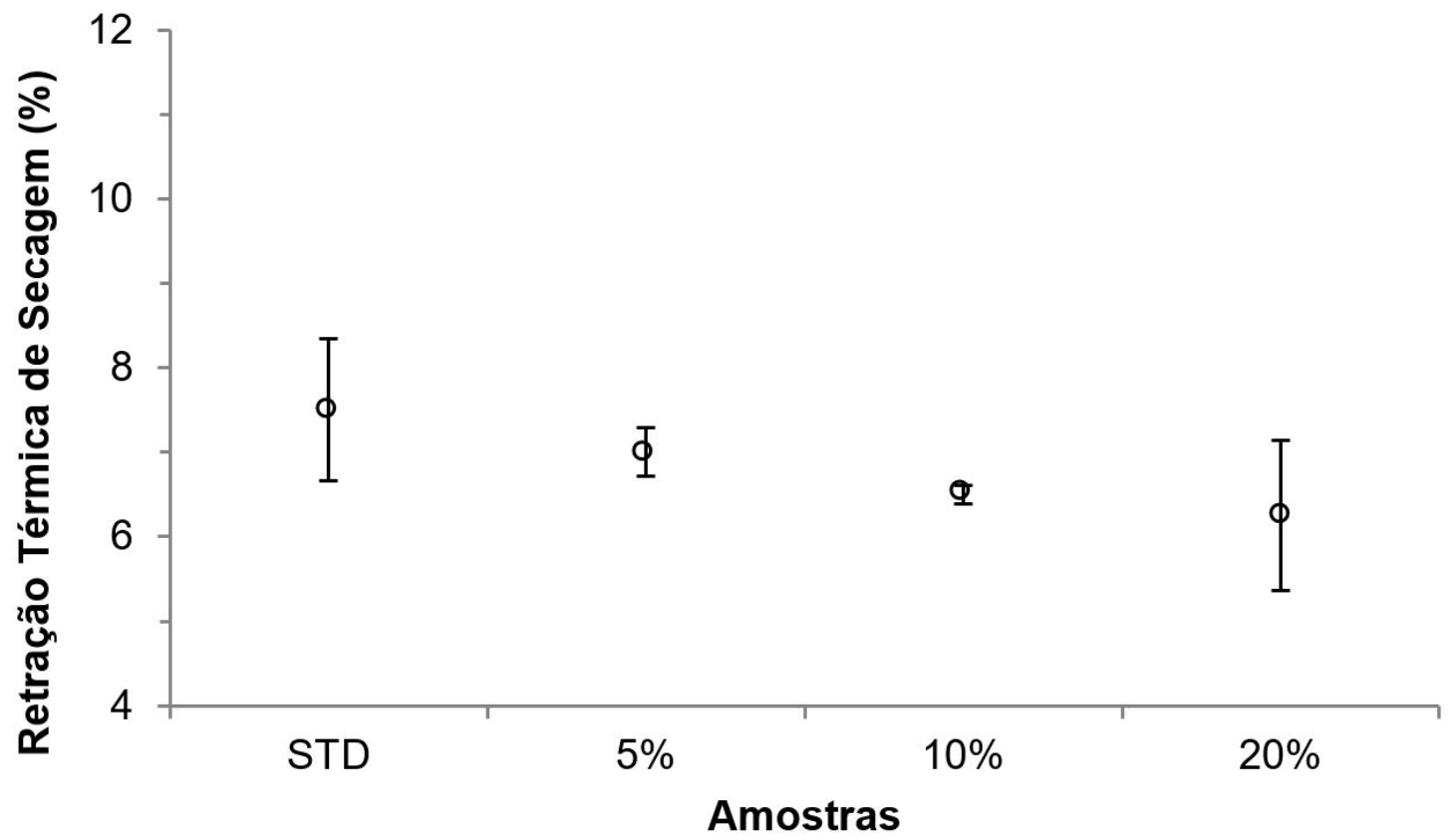

Figura 01: Gráfico com os valores obtidlos para Retração térmica linear de secagem.

A retração de secagem varia de acordo com a plasticidade do material argiloso e não pode ser muito elevada para não apresentar dificuldades no processo de fabricação. É possível afirmar que a argila tem um alto teor de plasticidade, apenas observando sua retração durante a secagem. Ainda pode-se observar que de acordo que o percentual de resíduo foi incorporado na massa padrão, à retração diminui. A Retração de 
secagem não pode exceder a $6 \%$ para evitar problemas no processo ${ }^{27}$, esse valor foi marginalmente obtido com a adição de $20 \%$ de resíduo, reduzindo a retração em 1,25\% comparada à massa padrão (STD).

Os materiais não-plásticos atuam na etapa de conformação e secagem, com a função de diminuir a retração das peças e ajudando na secagem. Estes materiais trabalham em equilíbrio com os materiais plásticos, controlando as transformações e deformações. Os materiais não-plásticos podem se apresentar ainda como inertes, vitrificantes e fundentes, na fase de queima, onde há mudanças na estrutura física das peças, seja ela expansão ou retração ${ }^{28}$. A retração de queima é considerada ótima quando seu valor é menor que $1,5 \%$ com a situação aceitável entre 1,5 a $3 \%{ }^{29}$. Na Figura 02 , apresenta os resultados obtidos para retração de queima nas três queimas realizadas.

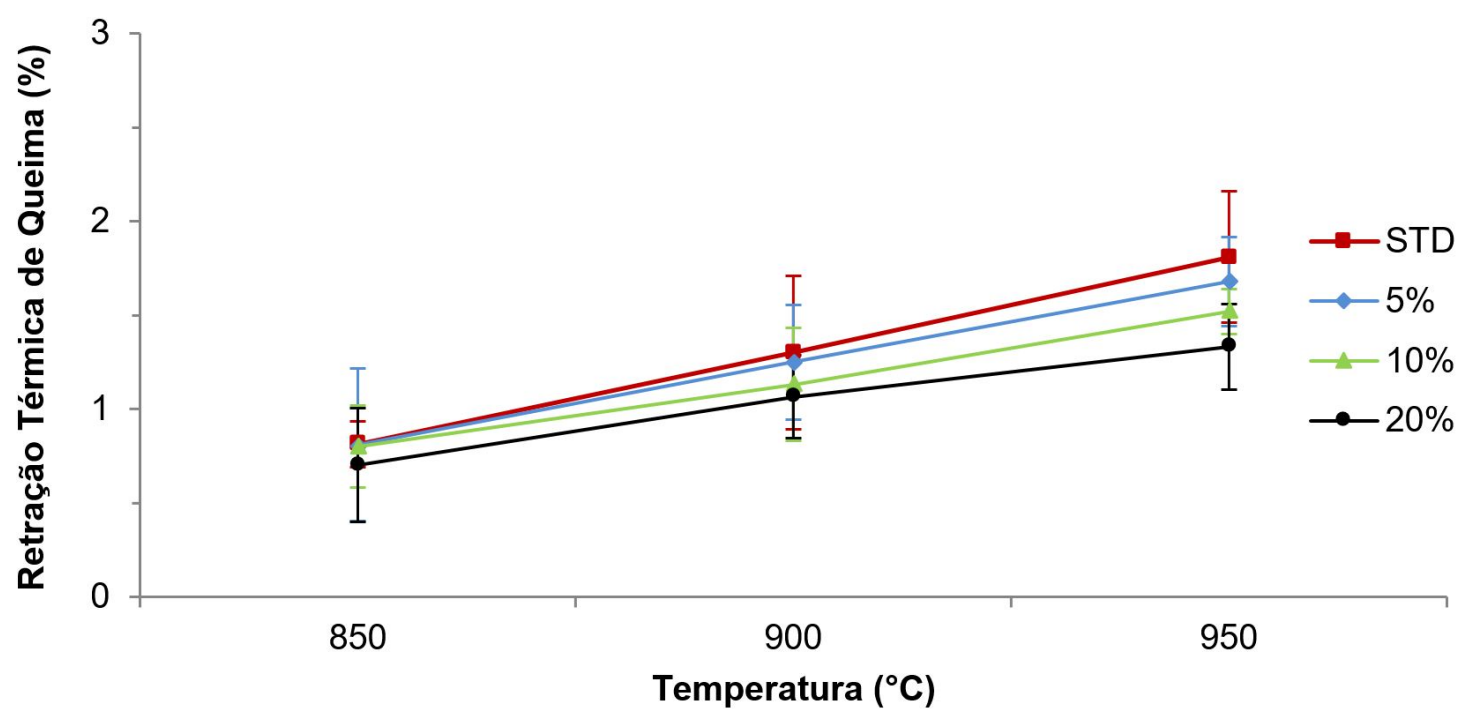

Figura 02: Gráfico com os valores obtidos para Retração térmica linear de queima com $850^{\circ} \mathrm{C}, 900^{\circ} \mathrm{C}$ e $950^{\circ} \mathrm{C}$.

É possível observar que mesmo com a adição do resíduo, os valores se mantiveram próximos, todavia, com o aumento da temperatura, obteve-se maior retração. Esse fenômeno ocorre quando à alteração da quantidade de calor durante a queima excedendo os limites aceitáveis da matéria-prima, ocasionando a perda de água de constituição, resultando no empacotamento mais próimo das partículas ${ }^{30}$. $\mathrm{O}$ aumento de temperatura acarreta uma maior retração linear de queima, originando tendências à diminuição da expansão térmica total ${ }^{31}$. Em $850{ }^{\circ} \mathrm{C}$ todas as amostras se manteram no dentro do limite descrito como ótimo, com uma diferença de apenas $0,1 \%$ entre a STD e $20 \%$. Com o aumento de temperatura para $900{ }^{\circ} \mathrm{C}$, houve um aumento médio de $0,40 \%$ da retração das amostragens, porém, se mantiveram dentro do parâmetro chamado de ótimo. A $950{ }^{\circ} \mathrm{C}$ as peças mantiveram um aumento médio de $0,40 \%$ de retração, e ultrapassaram aos $1,5 \%$ de que lhes deixam na situação aceitável, ou seja, a incorporação do resíduo não afetou negativamente nesse ensaio.

Em caráter qualitativo, a retração total (secagem e queima) não deve exceder a $12 \%$, sob o risco de aparecimento de deformações ou trincas no produto final27. Já em avaliação a portaria no 16/11 estabelecida pelo INMETRO ${ }^{32}$, é obrigatório o ensaio atender ao item "5 - Amostragem e Tolerância" tabela "V" da portaria em questão ou a NBR 15270/2005 23,24 especificada no ítem "4.5.2 Dimensões de Fabricação", sendo o valor permitido para tolerância especificada no ítem "5.1 Tolerância Dimensional", ambas correspondentes $\mathrm{a} \pm 3 \mathrm{~mm}$.

No ensaio de Absorção de água, ilustrado na Figura 03, pode-se observar que à medida que o resíduo foi adicionado à massa padrão, ouve um aumento de absorção na peça, esse fenômeno se dá, pois com a incorporação do resíduo haverá um aumento da porosidade da peça, e as duas propriedades estão ligadas, ou seja, o contato com a água preencherá higroscopicamente os poros dos corpos-de-prova, aumentando assim, 
a absorção ${ }^{33}$. Outro fator a se observar, é que com o aumento da temperatura de queima, houve uma diminuição na absorção de água das peças, haja vista que com maior temperatura há maior retração devido à sinterização, com isso ocasionará uma diminuição dos poros através do fenômeno de vitrificação, densificando a peça, observado em estudos de Phonphuak, Kanyakam e Chindaprasirt (2016) ${ }^{30}$.

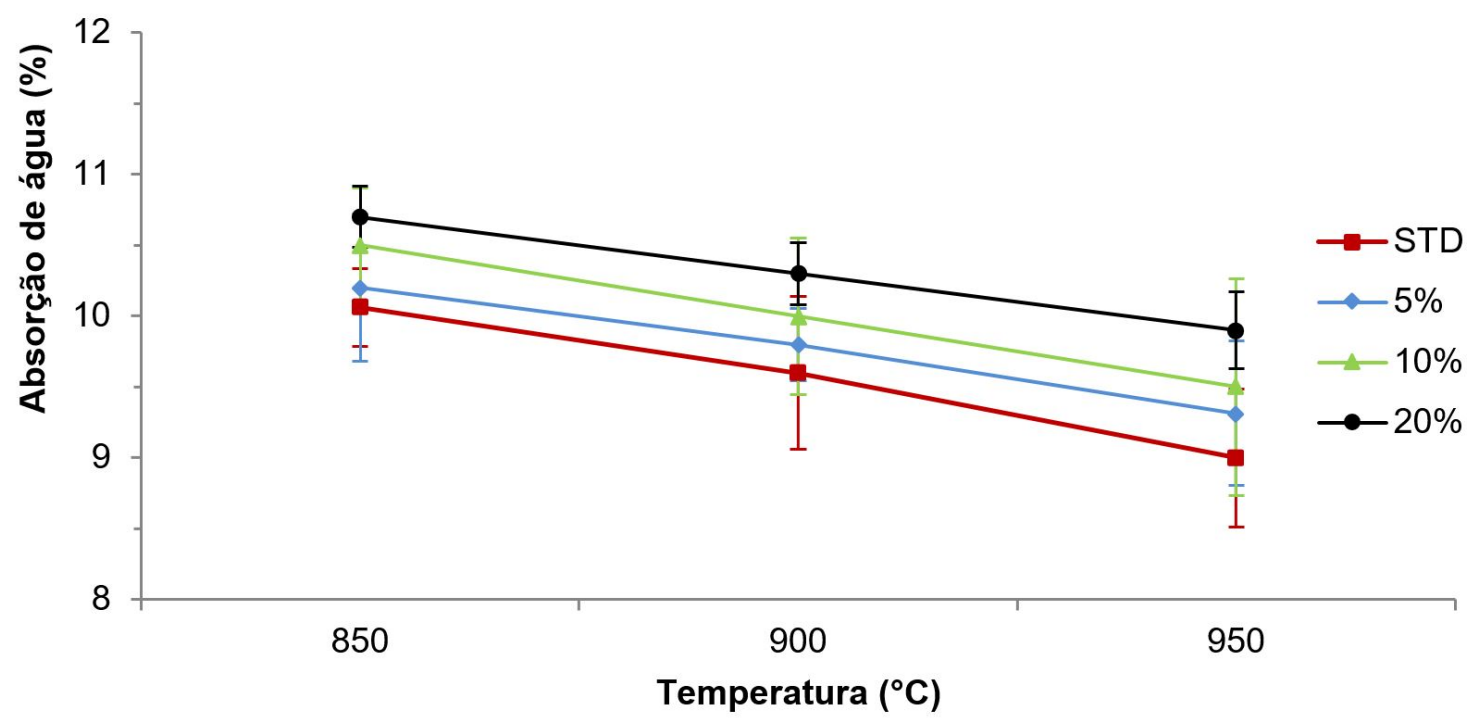

Figura 03: Gráfico com os valores obtidos para Absorção de água em $850{ }^{\circ} \mathrm{C}, 900{ }^{\circ} \mathrm{C}$ e $950{ }^{\circ} \mathrm{C}$.

A NBR 15270/2005 23,24 estabelece valores máximos e mínimos que devem ser obedecidos para absorção de água, onde não deve ser inferior a $8 \%$ e nem superior a $22 \%$. Tais valores obrigatoriamente têm que ser seguidos, uma vez que blocos de vedação da cerâmica vermelha tem sua pior condição física, quando está em contato com a água ${ }^{22}$. Nenhuma das amostras foi rejeitada, obedecendo a tabela 8 da referida norma técnica, que dá tolerância de uma amostra.

O ensaio de perda ao fogo fornece informações relativas à presença de matéria orgânica e substâncias voláteis no material amostrado ${ }^{34}$. Os resultados obtidos podem ser observados na Tabela 03.

Tabela 03: Resultados de Perda ao Fogo.

\begin{tabular}{cccccccc}
\hline \multirow{2}{*}{ Amostras } & \multicolumn{7}{c}{ Temperaturas $\left(\mathbf{~}^{\mathbf{C}}\right)$} \\
\cline { 2 - 7 } & \multicolumn{3}{c}{$\mathbf{8 5 0}$} & \multicolumn{3}{c}{$\mathbf{9 0 0}$} & \multicolumn{3}{c}{$\mathbf{9 5 0}$} \\
\hline STD & 6,105 & & $\pm 0,165$ & 6,276 & $\pm 0,099$ & 6,369 & $\pm 0,105$ \\
$\mathbf{5 \%}$ & 6,211 & & $\pm 0,219$ & 6,157 & $\pm 0,083$ & 6,352 & $\pm 0,150$ \\
$\mathbf{1 0 \%}$ & 6,073 & & $\pm 0,094$ & 6,250 & $\pm 0,080$ & 6,439 & $\pm 0,086$ \\
$\mathbf{2 0 \%}$ & 5,821 & & $\pm 0,815$ & 6,098 & $\pm 0,200$ & 6,314 & $\pm 0,101$ \\
\hline
\end{tabular}

A massa padrão (STD) manteve num percentual na casa dos $6 \%$ de perda ao fogo, tendo um leve aumento com maiores temperaturas, enquanto a formulação com $20 \%$ de resíduo saiu de $5,82 \%$ aos $850^{\circ} \mathrm{C}$ para $6,31 \%$ à $950^{\circ} \mathrm{C}$; essa leve mudança é explicada pela variação relacionada as variáveis do processo, tais como perda de água associada a hidróxidos, água de constituição de argilominerais e matéria orgânica eliminada durante o processo de queima; o que comprova que entre 850 e $950^{\circ} \mathrm{C}$ o uso de resíduo não propicia acarretar danos ao produto ${ }^{35}$.

Vale ressaltar, que durante a queima, algumas transformações acontecem na estrutura da argila, o que explica a perda ao fogo. Os argilominerais quando aquecidos até $150^{\circ} \mathrm{C}$, perdem água dos poros e a água adsorvida, e entre $400{ }^{\circ} \mathrm{C}$ e $900^{\circ} \mathrm{C}$ ocorre a expulsão da água ligada estruturalmente sob forma de grupos $\mathrm{OH}^{-}$. Uma série de 
mudanças físicas e químicas, que acontecem no decorrer do aumento de temperatura, tais fenômenos podem implicar na perda ao fogo ${ }^{36}$.

A ultima propriedade analisada, foi o teste de resistência mecânica, realizada em duas etapas, com as peças cruas e secas (Figura 04), a fim de se observar o comportamento das peças para manuseio antes do processo de queima, e com as peças pós-queima (Figura 05).

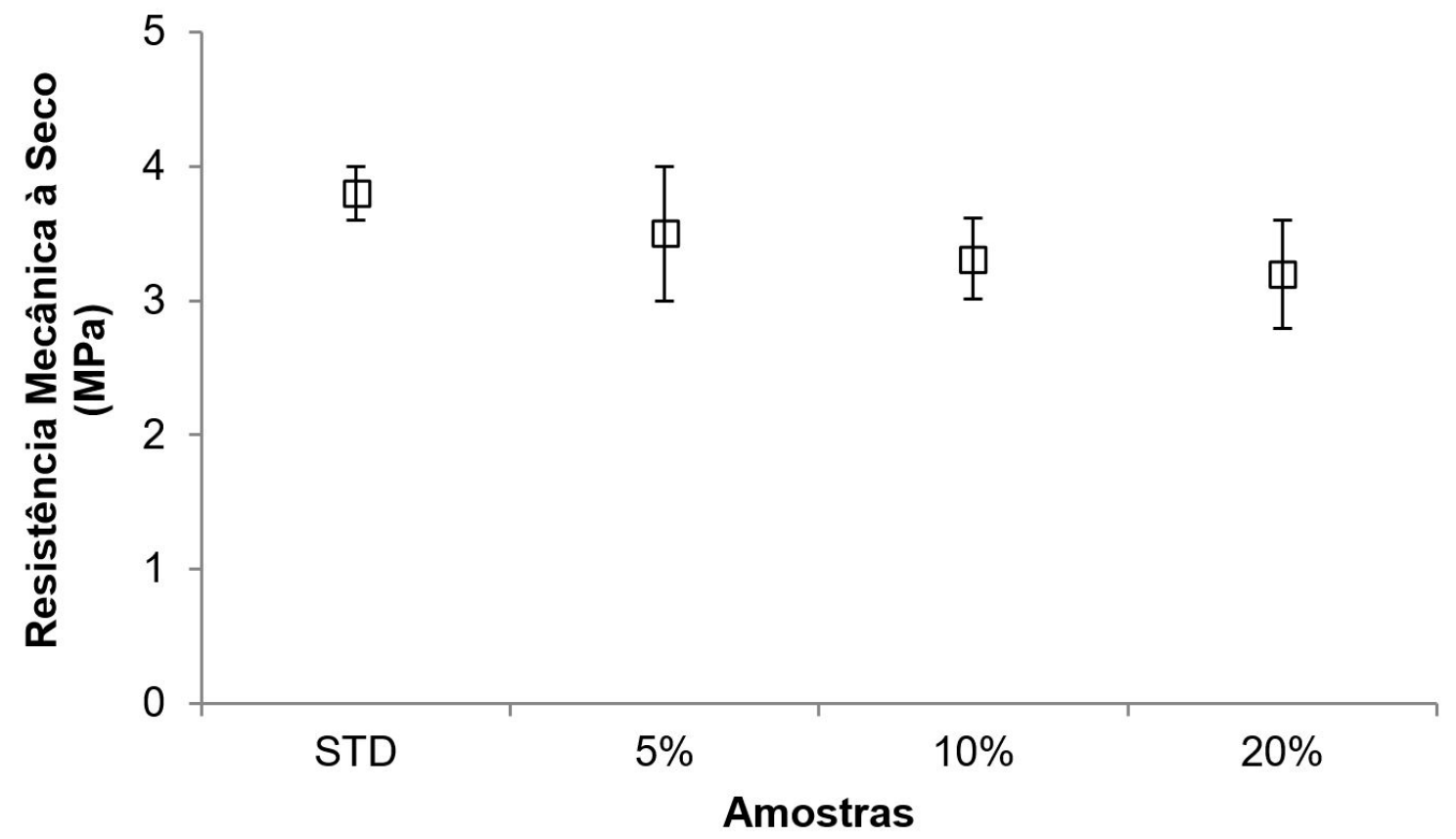

Figura 04: Gráfico com os valores de Resistência Mecânica a seco.

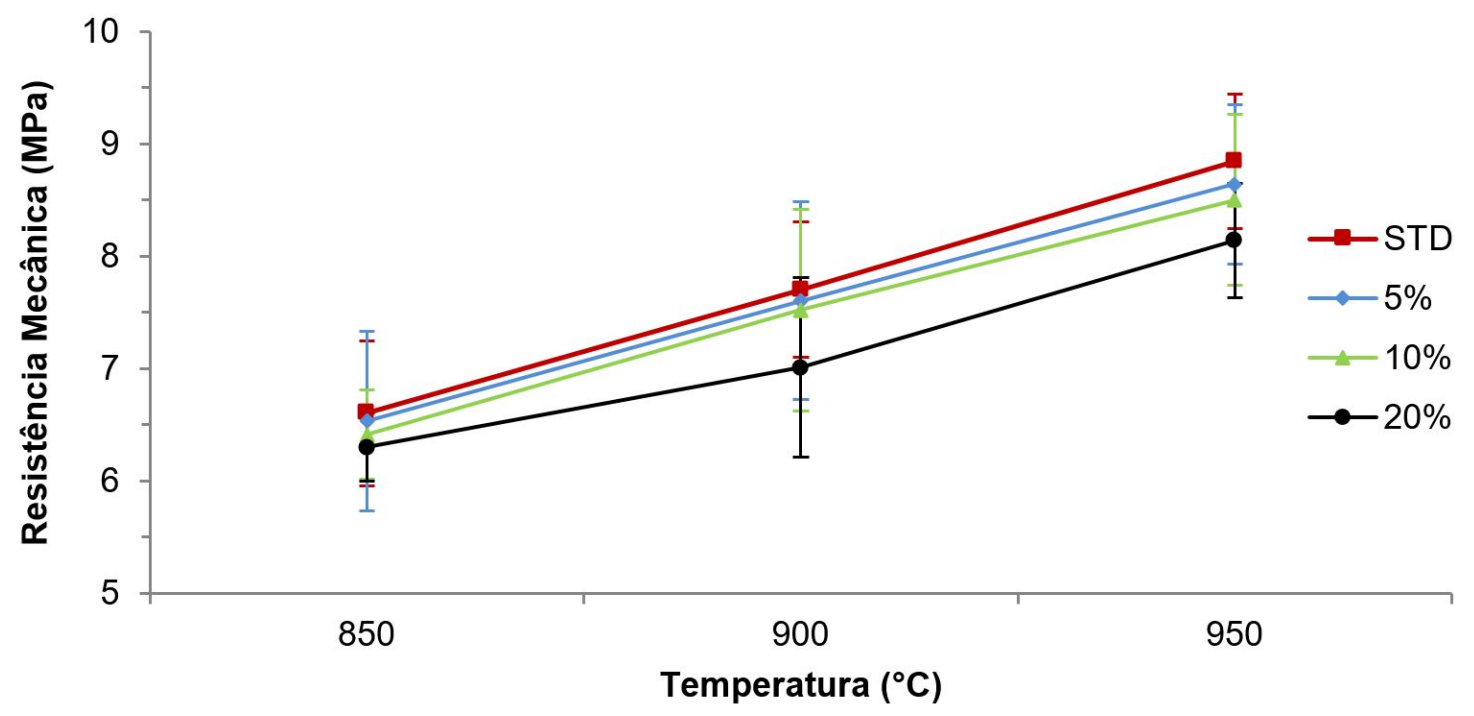

Figura 05: Gráfico com os valores de Resistência Mecânica.

Pode-se observar que há uma leve variação de acordo que o resíduo foi incorporado, diminuindo a resistência da peça crua e seca, porém essa diferença de $0,6 \%$ da amostra padrão (STD) à formulação com $20 \%$ de resíduo mostra que a adição do material não haverá uma expressiva influência negativa. Não há um valor estabelecido por norma, para que as peças cruas atendam, mas conhecer as informações da peça ainda 
verde é importante ${ }^{37}$, no caso da resistência mecânica à seco, é relevante para que as peças não sejam danificadas durante manuseio de carga de vagões dos fornos.

Nesse ultimo ensaio, o de resistência mecânica dos corpos-de-prova, pode-se observar que em $850{ }^{\circ} \mathrm{C}$ há um percentual muito baixo de diferença entre a massa padrão (STD) e $20 \%$ do material adicionado (apenas $0,3 \%$ ), o que não interfere na qualidade do produto. Com o aumento da temperatura de queima, visualiza-se que há um aumento na resistência das peças, atingindo maior percentual a $950{ }^{\circ} \mathrm{C}$. Importante ressaltar que em ambas as temperaturas de queima, o melhor resultado de resistência mecânica foi da massa padrão (STD), diminuindo de acordo com o percentual de resíduo adicionado, todavia, por ficarem com valores muito aproximados, conclui-se que a incorporação do material não afetou negativamente nesse ensaio.

Um fato importante a se considerar é que as propriedades determinadas seguiram o mesmo comportamento, diminuição da absorção de água e aumento da retração linear e resistência mecânica, como observado em estudos realizados por Dutra et al. (2009) ${ }^{38}$.

\section{CONSIDERAÇÕES FINAIS}

Foi possível observar nos testes realizados que o resíduo incorporado obteve bom comportamento nas propriedades tecnológicas estudadas. Na matéria-prima padrão com até $20 \%$ de escória aplicada na massa não interferiu negativamente suficiente para que os ensaios reprovassem mediante os resultados alcançados em todas as temperaturas estudadas. Entretanto, em determinadas propriedades o resultado foi satisfatório, como no ensaio de retração térmica de secagem, que o maior percentual de resíduo obteve os menores índices de retração, mostrando que a aplicação da matéria-prima alternativa pode melhorar algumas das propriedades físicas da cerâmica.

Conclui-se que o resíduo pode ser aplicado ao processo produtivo junto a essa matéria-prima padrão em até $20 \%$ e temperatura de $850^{\circ} \mathrm{C}$ podendo-se atingir até $950{ }^{\circ} \mathrm{C}$.

\section{Referencias}

[1] QUEIROZ, M.T.A., SANTOS, G.P.P., CALDEIRA, B.R., OLIVEIRA, C.L., Resultados preliminares: utilização da escória de alto forno a carvão vegetal em estruturas de concreto. IV SEGeT - Simpósio de Excelência em Gestão e Tecnologia, Associação Educacional Don Bosco - AEDB, Resende - RJ, 8 p. 2004.

[2] SHREVE, R.N. Indústrias de processos químicos. In: SHREVE, R.N., BRINK, J.A. Jr. (Org.); Tradução de Horácio Macedo. Rio de Janeiro: Guanabara, 1977.

[3] ALMEIDA, M.L.B., MELO, G.C.B. Alternativas de usos e aplicações dos resíduos sólidos das indústrias independentes de produção de ferro-gusa do estado de Minas Gerais. $21^{\circ}$ Congresso Brasileiro de Engenharia Sanitária e Ambiental - Associação Brasileira de Engenharia Sanitária - ABES. João Pessoa - PB, 13 p., 2001.

[4] POHLMANN, J.G., BORREGO, A.G., OSÓRIO, E., DIEZ, M.A., VIELA, A.C.F. Combustion of eucalyptus charcoals and coals of similar volatile yield aiming at blast furnace injection in a $\mathrm{CO}_{2}$ mitigation environment. Journal of Cleaner Production, v. 129, p. 1-11, 2016.

[5] WIKLUND, C., HELLE, M., SAXÉN, H. Economic assessment of options for biomass pretreatment and use in the blast furnace. Biomass and Bioenergy, v. 91, p. 259-270, 2016.

[6] WANG, C., LARSSON, M., LÖVGREN, J., NILSSON, L., MILLIN, P., YANG, W., HASSAN, S., HULTGREN, A. Injection of solid biomass products into the blast furnace and its potential effects on an integrated steel plant. Energy Procedia, v. 61, p. 2184-2187, 2014.

[7] BRASIL. Ministério do Meio Ambiente - MMA. Energias Renováveis: Biomassa. Disponível em: http://www.mma.gov.br. Acesso em 14 de Abril de 2015.

[8] ANEEL - Agencia Nacional de Energia Elétrica. Disponível em: www.aneel.gov.br. Acesso em 15 de Abril de 2015.

[9] PRETO, E.V., MORTOZA, G.L. Geração de Energia Elétrica Utilizando Biomassa. (Trabalho de Conclusão de Curso) Engenharia Elétrica, Universidade de Brasília - UnB, Brasília - DF, 82 p. 2010.

[10] ABNT - ASSOCIAÇÃO BRASILEIRA DE NORMAS TÉCNICAS. NBR 10004/2004. Resíduos Sólidos - Classificação: Rio de Janeiro: ABNT, 2004, 71p.

[11] MENEZES, R.R.; NEVES, G.A.; FERREIRA, H.C. O estado da arte sobre o uso de resíduos como matérias-primas cerâmicas alternativas. Revista Brasileira de Engenharia Agrícola e Ambiental, v.6, n.2, p.303-313. 2002. 
[12] CALDAS, T.C.C., Reciclagem de resíduo de vidro em cerâmica vermelha. (Dissertação de Mestrado) Engenharia e Ciência de Materiais, Universidade Estadual do Norte Fluminense Darcy Ribeiro - UENF. Campos dos Goytacazes/ RJ, 89 p. 2012.

[13] TAHA, Y., BENZAAZOUA, M., HAKKOU, R., MANSORI, M. Coal mine wastes recycling for coal recovery and ecofriendly bricks production. Minerals Engineering, v. 107, p.123-138, 2017.

[14] SUTCU, M., ALPTEKIN, H., ERDOGMUS, E., ER, Y., GENCEL, O. Characteristics of fired clay bricks with waste marble powder addition as building materials. Construction and Building Materials, v. 82, p. 1-8, 2015.

[15] AHMAD, S., IQBAL, Y., MUHAMMAD, R. Effects of coal and wheat husk additives on the physical, thermal and mechanical proprieties of clay bricks. Boletín de la Sociedad Española de Cerámica y Vidrio, In Press, 2017.

[16] KAZMI, S.M.S., ABBAS, S., MUNIR, M.J., KHITAB, A. Exploratory study on the effects of waste rice husk and sugacane bagasse ashe in burnt clay bricks. Journal of Building Engineering, v. 7, p. 372-378, 2017.

[17] ELICHE-QUESADA, D., FELIPE-SESÉ, M.A., LÓPEZ-PÉREZ, J.A., INFANTES-MOLINA, A. Characterization and evaluation of rice husk ash and wood ash in sustentable clay matrix bricks. Ceramics International, v. 43 (1/A), p. 463-475, 2017.

[18] ADAZABRA, A.N., VIRUTHAGIRI, G., SHANMUGAM, N. Management of spent shea waste: Na instrumental characterization and valorization in clay bricks construction. Waste Management, v. 64, p. 286-304, 2017.

[19] ESCALERA, E., GARCIA, G., TERÁN, R., TEGMAN, R., ANTTI, M-L., ODÉN, M. The production of porous brick material from diatomaceous Earth and Brazil nut shell ash. Construction and Building Materials, v. 98, p. 257-264, 2015.

[20] ELICHE-QUESADA, D., LEITE-COSTA, J. Use of bottom ash from olive pomace combustion in the production of eco-friendly fired clay bricks. Waste Management, v. 48, p. 323-333, 2016.

[21] TORETTI, I., NUNES, E.B., BENINCÁ, A., REZIN, K.Z., CARGNIN, M. Estudo da determinação da plasticidade de matérias-primas cerâmicas utilizando o método de pfefferkorn. In: $1^{\circ}$ Simpósio de Integração Científica e Tecnológica do Sul Catarinense - SICT-Sul, Rev. Técnico Científica (IFSC), v. 3, n.1,p. 226-233, 2012

[22] ZACCARON, A., GALATTO. S.L., NANDI, V.S., FERNANDES, P. Incorporação de chamote na massa de cerâmica vermelha como valorização de resíduo. Cerâmica Industrial, v. 19, n. 3, p. 33-39, 2014.

[23] ABNT - ASSOCIAÇÃO BRASILEIRA DE NORMAS TÉCNICAS. NBR 15270-01/2005. Componentes Cerâmicos Parte 1: Blocos cerâmicos para alvenaria de vedação - Terminologia e requisitos: Rio de Janeiro: ABNT, 2005, 11p.

[24] ABNT - ASSOCIAÇÃO BRASILEIRA DE NORMAS TÉCNICAS. NBR 15270-03/2005. Componentes Cerâmicos Parte 3: Blocos cerâmicos para alvenaria estrutural e de vedação - Métodos de ensaio: Rio de Janeiro: ABNT, 2005, 27p.

[26] CROZETTA, J.R., NANDI, V.S., ROSSO, F., ZACCARON, A., NIERO, D.F. Influência da granulometria na plasticidade e retração de secagem das argilas. Cerâmica Industrial, v. 21 (1), p.21-29, 2016.

[27] LOYOLA, L.C., As Argilas e a Cerâmica Vermelha - I Seminário sobre competitividade na indústria cerâmica e olarias do este do Paraná, Curitiba - PR, 2004. 45 p.

[28] MOTTA, J.F.M., CABRAL JR., M., TANNO, L.C., ZANARDO, A. As matérias-primas cerâmicas. Parte II: Os minerais industriais e as massas da cerâmica tradicional. Revista Cerâmica Industrial, v. 7, n. 1, p. 33-40, 2002.

[29] DONDI, M. Caracterização tecnológica dos materiais argilosos: métodos experimentais e interpretação dos dados. Cerâmica Industrial, v. 11, n. 3, p. 36-40, 2006.

[30] PHONPHUAK, N., KANYAKAM, S., CHINDAPRASIRT, P. Utilization of waste glass to enhance physical-mecanical proprierties of fire clay brick. Journal of Cleaner Production, v. 112, p. 3057-3062, 2016.

[31] MARINO, L.F.B., BOSCHI, A.O. A expansão térmica de materiais cerâmicos. Parte II: Efeito das condições de fabricação. Cerâmica Industrial, v. 3, n. 1-2, 1998, pg. 23-33.

[32] BRASIL. Ministério do Desenvolvimento, Indústria e Comércio Exterior - MIDIC. Instituto Nacional de Metrologia, Normalização e Qualidade Industrial - INMETRO. Portaria Inmetro n 16, de 05 de janeiro de 2011. Diário Oficial da República Federativa do Brasil, Brasília, DF, pg. 6. 2011.

[33] FACINCANI, E., Tecnologia Cerâmica: Cerâmica estrutural. Tradução de Géol Jaime Pedrassani. São Paulo: Faenza Editrice do Brasil, 276p., II, 2002.

[34] DIAS, L.M.,BATALIONE, G., MORAIS, F.U., SOBRINO, J.F., RIBEIRO, M.C., LISBOA, M.S. Alternativa de destinação final do lodo de estação de tratamento de água: fabricação de blocos cerâmicos. In: XXIX Congreso Interamericano de Ingeniería Sanitaria y Ambiental, 29, San Juan, Porto Rico. Anais: AIDIS. Forjando el Ambiente que Compartimos. p.123, llus., 2004.

[35] FERNANDES, P., DONADEL, K., NANDI, V.S., MANTAS, P. O estudo da diminuição da rugosidade da superfície de telhas cerâmicas. Cerâmica Industrial, v. 17, n. 5-6, p. 42-46, 2012.

[35] OLIVEIRA, A.A. Tecnologia em Cerâmica. Criciúma-SC. Editora Lara, 176 p. 2011.

[36] RIELLA, H.G. Cerâmica - dos minerais à porcelana. $1^{\mathrm{a}}$ ed. Editora Tecart, São Paulo, 2010. 157p.

[37] NAIT-ALI, B., OUMMADI, S., PORTUGUEZ, E., ALZINA, A., SMITH, D.S. Thermal conductivity of ceramic green bodies during drying. Journal of the European Ceramic Society, v. 37 (4), p. 1839-1846, 2017.

[38] DUTRA, R.P.S.; VARELA, M.L.; NASCIMENTO, R.M.; GOMES, U.U.; MARTINELLI, A.E.; PASKOCIMAS, C.A. Estudo comparativo da queima rápida com a queima tradicional nas propriedades de materiais cerâmicos de base argilosa. Cerâmica v. 55 n. 333, p. 100-105, 2009. 